\title{
PHYSOSTIGMINE PROLONGS THE ELEMENTARY EVENT UNDERLYING DECAY OF INHIBITORY POSTSYNAPTIC CURRENTS IN APLYSIA
}

\author{
ROY L. WHITE ${ }^{2}$ AND DANIEL GARDNER ${ }^{3}$ \\ Department of Physiology and Biophysics, Cornell University Medical College, New York, New York 10021
}

Received May 3, 1983; Revised July 18, 1983; Accepted July 19, 1983

\begin{abstract}
Inhibitory postsynaptic currents (IPSCs) recorded at cholinergic synapses between identified neurons of the buccal ganglia of Aplysia decay exponentially. IPSC decay has been ascribed to a receptor-channel-dependent kinetic process, rather than to changes in subsynaptic acetylcholine (ACh) concentration, but is prolonged by the anticholinesterase eserine. Our data are consistent with a direct effect of $1.6 \times 10^{-4} \mathrm{M}$ eserine on an elementary channel process. IPSC decay remains single exponential during eserine prolongation, suggesting that eserine slows the kinetic process responsible for decay, rather than substituting an additional kinetic process. In either control sea water or eserine, noise spectra computed from currents induced by pressure ejection of ACh are fitted by the sum of two Lorentzians. The slow corner frequency $f_{1}$ is reduced from 6.3 to $3.5 \mathrm{~Hz}$ by eserine, consistent with a direct eserine action on receptor-channel kinetics, whereas apparent single-channel conductance was unchanged. Both IPSCs and ACh noise recorded in the same cells were comparably slowed by eserine. In eserine, decay time constant $\tau$ agreed with noise $f_{1}$; however, $\tau$ and $f_{1}$ in control sea water differed by $31 \%$. The discrepancy may be accounted for by invoking an additional component to the recorded noise spectra, perhaps produced by synaptically active choline. In addition to the direct effect on kinetics, prolonged exposure to eserine produces a slow extra component to the IPSC decay tail.
\end{abstract}

Transmitter-activated currents at a variety of synapses and neuromuscular junctions appear to decay exponentially (Kordas, 1972; Magleby and Stevens, 1972; Katz and Miledi, 1973; Gage and McBurney, 1975; Colquhoun and Hawkes, 1977; Gardner and Stevens, 1980; Dionne and Parsons, 1981). A theory accounting for the time courses of these synaptic currents explains decay as the exponential relaxation of kinetically distinguishable states, usually identified with a conformational change closing open synaptic current channels, the dissociation of agonist from a receptor, or a combination of both events (reviewed by Colquhoun and Hawkes, 1977). In general, the relaxation process is different from the removal of neurotransmitter from the region of postsyn-

\footnotetext{
1 This work was supported by National Institutes of Health Grant NS11555, Research Career Development Award NS00003, and Postdoctoral Fellowship NS 05971.

${ }^{2}$ Present address: Department of Neuroscience, Albert Einstein College of Medicine, 1300 Morris Park Avenue, Bronx, NY 10461.

${ }^{3}$ To whom reprint requests should be addressed, at Department of Physiology C-534, Cornell University Medical College, 1300 York Avenue, New York, NY 10021.
}

aptic receptors by either diffusion or inactivation. At the frog neuromuscular junction, anticholinesterases such as neostigmine prolong endplate currents (Magleby and Stevens, 1972) without apparent effect on the duration of the elementary event (Katz and Miledi, 1973). Various mechanisms have been proposed to reconcile these findings (Hartzell et al., 1975; Magleby and Terrar, 1975; Kordas, 1977).

Recording from neurons of Aplysia buccal ganglia, Gardner and Stevens (1980) have shown that cholinergic inhibitory postsynaptic currents (IPSCs) decay exponentially. They suggested that this decay reflects one of the class of relaxation processes mentioned above, a conformational change closing open synaptic channels with exponentially distributed lifetime. Again, as in the case of other synaptic currents, they found that an anticholinesterase, here physostigmine sulfate (eserine), prolongs exponential decay of IPSCs. If Gardner and Stevens (1980) were correct in their assignment of the decay process, and if this same process is responsible for IPSC decay even in the presence of eserine, then the theory would predict that eserine should modify the lifetime of the elementary event recorded in the presence of con- 
stant or near-constant acetylcholine $(\mathrm{ACh})$ concentration. We now report that spectra of $\mathrm{ACh}$ current fluctuations are consistent with a direct action of eserine on the receptor-channel complex. In addition, IPSC decay remains exponential during the introduction of eserine. We interpret the absence of multi-component decay as further evidence that eserine prolongs the synaptic current relaxation process seen in control conditions, rather than substituting a new rate-limiting step. Eserine's effect differs from those reported for other anticholinesterases on these neurons, supporting the hypothesis that eserine has actions different from acetylcholinesterase (AChE) inhibition. Finally, we report an additional effect of eserine: following the initial effect on receptor-channel kinctics, there exists a more slowly developing effect on synaptic currents which may represent a late inhibition of AChE-mediated hydrolysis of transmitter.

A preliminary report of some of these findings has been presented to the Society for Neuroscience (White and Gardner, 1980).

\section{Materials and Methods}

Neurons of the buccal ganglia of Aplysia californica were employed in this study. Source and storage of specimens, and dissection of ganglia, were as described previously (Gardner, 1977; Gardner and Stevens, 1980). IPSCs and agonist-induced currents were recorded from somata of inhibitory follower cells BL or BR 3 or 8, identified using the criteria of Gardner and Kandel (1977).

Glass microelectrodes were filled with $\mathrm{KCl}$ and bevelled to a resistance of 1.5 to 2.0 megohms. The voltage clamp used the circuit of Gardner (1977), modified to provide a low frequency gain in the final stage essentially equal to the open-loop gain of the output amplifier ( $\mathbf{F}$. Sigworth, personal communication). Currents were recorded either by a chlorided Ag wire feeding a virtualground amplifier or else via a resistor in series with the current-passing electrode. Noise signals to be analyzed in the frequency domain were amplified, then fed through an active filter with four-pole Butterworth high-pass and low-pass sections (Model 4212, Ithaco, Ithaca, NY). The usual passband with 0.63 to $500 \mathrm{~Hz}$; at these settings, attenuation at $1 \mathrm{~Hz}$ is about $0.1 \mathrm{~dB}$. IPSCs were analyzed in time domain after filtering by the same device in Bessel configuration.

Inhibitory follower cells were impaled with two microelectrodes. In addition, IPSCs were elicited in the follower cells by direct intracellular stimulation of presynaptic neurons BL or BR 4 or 5. Criteria for voltage control of the synaptic site have been discussed previously (Gardner, 1980; Gardner and Stevens, 1980). Agonist-induced currents were elicited by the application of ACh via pressure ejection from a micropipette onto sensitive areas of the neuropil adjacent to the soma of the postsynaptic neuron. To reduce postsynaptic receptor desensitization due to diffusion of $\mathrm{ACh}$ from the tip of the pipette, negative pressure was applied while positioning the pipette. Concentration fluctuations of ACh were minimized by using diffusional distances greater than $100 \mu \mathrm{m}$. Following recordings in control artificial sea water (ASW), the bath was perfused with ASW contain- ing physostigmine sulfate (eserine, Calbiochem), and IPSCs of ACh-induced current fluctuations were recorded again. To reduce the incidence of spontaneous IPSCs both control and eserine ASW contained $60 \mathrm{~mm}$ $\mathrm{Ca}^{2+}$. Experiments were performed at room temperature: 18 to $20^{\circ} \mathrm{C}$.

Digitization of records and subsequent computer analysis were as described previously (Gardner and Stevens, 1980), with exponentially decaying IPSCs fitted using the method of least squares. In several cases, computergenerated exponentials were fitted to IPSCs by eye. Power density spectra calculated from current records taken before or after the addition of ACh were subtracted from spectra calculated from current records taken during the application of $\mathrm{ACh}$. Current records were rejected if they contained spontaneous synaptic currents. Averages of up to $32 \mathrm{ACh}$ spectra from each experimental run (ASW or eserine) were taken.

\section{Results}

Inhibitory follower cells BL or BR 3 or 8 were voltage clamped at -100 to $-150 \mathrm{mV}$. At these membrane potentials, a single action potential elicited in the presynaptic cell (BR or BL 4 or 5) produced, without failure, an inward current in the follower cell. Initially, this current reversed at about $-70 \mathrm{mV}$, with the reversal potential becoming more positive over time as $\mathrm{Cl}^{-}$ions entered the cell from KCl-filled intracellular electrodes. Other evidence that these IPSCs are due to conductance increases to $\mathrm{Cl}^{-}$has been presented previously (Gardner and Kandel, 1977).

Eserine slows the rate-limiting step determining decay. Gardner and Stevens (1980) showed that buccal ganglia IPSCs decayed exponentially with single time constant, and suggested that a process related to channel lifetime or receptor occupancy, rather than transmitter supply or removal, was the rate-limiting step determining this decay. Gardner and Stevens (1980) also hypothesized a direct effect of eserine on channel lifetime.

We therefore investigated whether eserine slowed the rate-limiting step seen in the absence of anticholinesterases, as the Gardner and Stevens hypothesis would predict, or whether eserine slows an additional, formerly fast process and thereby substitutes a new rate-limiting step. IPSCs were recorded in each of five cells at short intervals after addition of $1.5 \times 10^{-5}$ to $1.5 \times 10^{-4} \mathrm{M}$ eserine to the sea water bath. Eserine produces a gradual prolongation of the IPSC with $\tau$, the decay time constant, increased an average $2.7 \pm 0.5$ times (SEM, $n=5$ ). The effect is complete within $10 \mathrm{~min}$. Three sample currents recorded in one cell are shown in Figure 1. If a new ratelimiting step were being substituted for a previous one, IPSCs recorded during wash-in should reflect both processes and, consequently, decay with kinetics more complex than single exponential. However, decay remains single exponential during eserine wash-in, with a gradual increase in the time constant (Fig. 1). These results indicate that eserine alters the existing rate-limiting step seen in control conditions.

Eserine slows ACh-induced fluctuations. Gardner and Stevens (1980) reported that eserine increased IPSC decay time constants by a factor of 1.7 . The hypothesis 
A

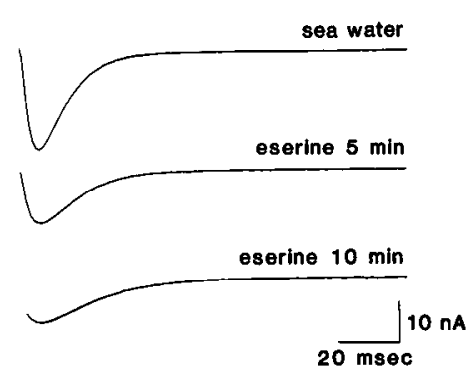

B

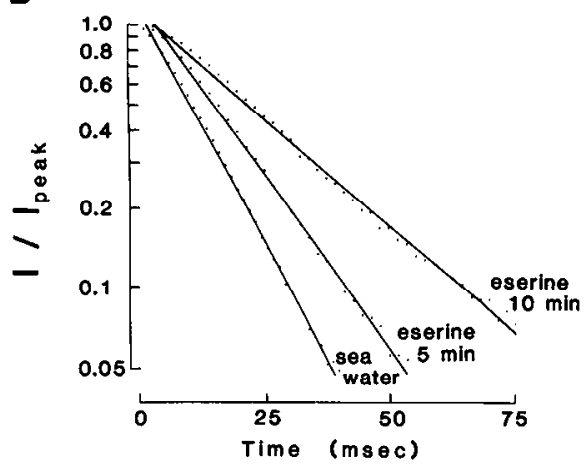

Figure 1. Eserine prolongs IPSCs by slowing the rate-limiting step. $A$, Three IPSC traces recorded in control sea water, and at 5 and $10 \mathrm{~min}$ after addition of $1.5 \times 10^{-5} \mathrm{M}$ eserine to the bath. Traces were recorded at a clamp holding potential of $-125 \mathrm{mV} . \mathrm{B}$, The dotted lines are semilogarithmic decay plots of the three IPSCs shown in $A$. Each decay is least squares fit by a computer-generated solid line of $\tau=10.1 \mathrm{msec}$ (sea water), $\tau=13.6 \mathrm{msec}$ (eserine $5 \mathrm{~min}$ ), and $\tau=22.1 \mathrm{msec}$ (eserine 10 $\mathrm{min}$ ). The eserine $5 \mathrm{~min}$ trace is adequately fit by a single exponential with time constant intermediate between those for the other two traces, suggesting that eserine produces a graded slowing of the control rate-limiting step rather than adding an additional slow process to decay.

that eserine has a direct effect on channel kinetics predicts that the elementary process lifetime calculated from ACh noise spectra should be prolonged by the same amount. In order to test this prediction, we applied ACh and measured resulting noise spectra. We found, as did Gardner and Stevens, that spectra could not adequately be fitted by the single-component Lorentzian curve, with corner frequency $f_{c}=1 /(2 \pi \tau)$, predicted by a simple two-state model for synaptic channels. Instead, a double Lorentzian expression of the form

$$
S(f)=\frac{A_{1}}{1+\left(f / f_{1}\right)^{2}}+\frac{A_{2}}{1+\left(/ / / f_{2}\right)^{2}}
$$

where $S(f)$ is the current spectral density as a function of frequency, $f_{1}$ and $f_{2}$ are the slower and faster corner frequencies, and $A_{1}$ and $A_{2}$ are amplitudes, was required. In control sea water, spectra were double Lorentzian with average corner frequencies $f_{1}=6.3 \pm 0.4 \mathrm{~Hz}$ and $f_{2}$ $=46 \pm 3 \mathrm{~Hz}(n=18)$. (In six additional cells, ACh noise spectra had a visible $1 / f$ component; these cells were not analyzed further.) If the $6.3 \mathrm{~Hz}$ process represents the kinetic event responsible for IPSC decay, and if eserine prolongs this event, then eserine should correspondingly lower the slow corner frequency to about $6.3 \mathrm{~Hz} / 1.7=$ $3.7 \mathrm{~Hz}$. In eserine, the average $f_{1}=3.5 \pm 0.3 \mathrm{~Hz}(n=8)$, consistent with the hypothesis. (In one cell, included in the averages, $f_{1}$ in eserine was slightly faster than $f_{1}$ in the same cell in sea water). We saw no clear effect of eserine on the fast component; $f_{2}$ was $40 \pm 4 \mathrm{~Hz}$ after eserine. Figure 2 shows an example of $\mathrm{ACh}$ noise spectra recorded from one cell before and after eserine treatment. A double Lorentzian curve, with $f_{1}=8.4 \mathrm{~Hz}$ and $f_{2}=31$ $\mathrm{Hz}$, has been fitted to the spectrum recorded in sea water (Fig. 2, upper plot, solid line). A curve with these same corner frequencies (Fig. 2, lower plot, dashed line) did not adequately fit the spectrum recorded in eserine, which required a curve with $f_{1}=4.2 \mathrm{~Hz}$ and $f_{2}=24 \mathrm{~Hz}$ (Fig. 2, lower plot, solid line). The lowering of $f_{1}$ suggests that eserine exerts its effect directly upon the elementary process responsible for the decay of the synaptic current; this process is unlikely to be transmitter removal from the synaptic cleft.

The amplitude, $\gamma$, of the elementary event responsible for the process with the slower corner frequency was

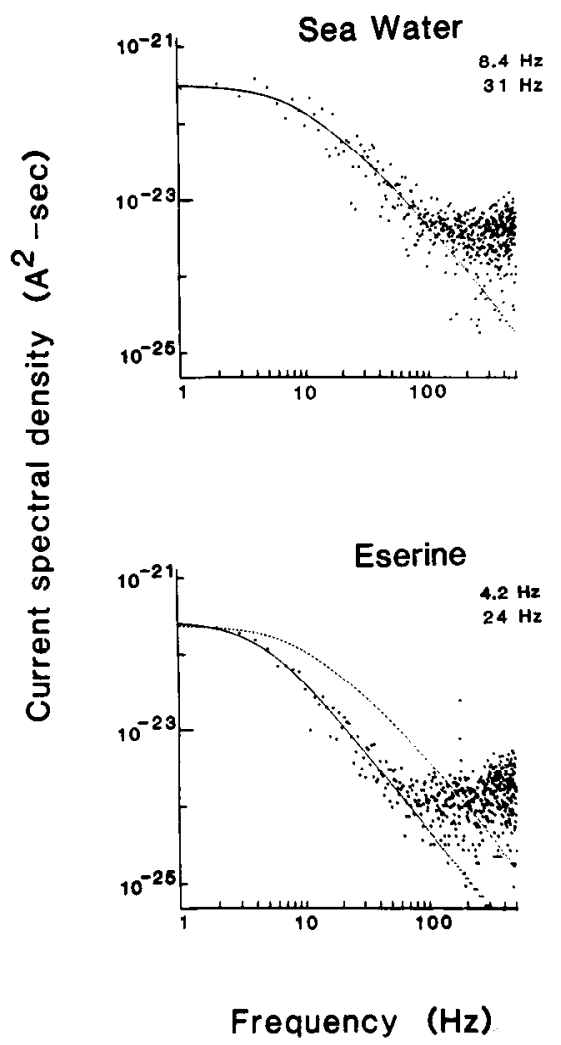

Figure 2. Eserine slows ACh fluctuations. The graphs plot current spectral density of $\mathrm{ACh}$-induced fluctuations as a function of frequency. In Sea Water, the ACh noise is fitted by eye with a computer-generated double Lorentzian curve with corner frequencies of $8.4 \mathrm{~Hz}$ and $31 \mathrm{~Hz}$, and zero-frequency amplitudes of $3.2 \times 10^{-22}$ and $1.2 \times 10^{-24} \mathrm{~A}^{2}$-sec. After treatment with 1.5 $\times 10^{-4} \mathrm{M}$ Eserine, the ACh noise spectrum can no longer be fit by a Lorentzian with $8.4 \mathrm{~Hz}$ and $31 \mathrm{~Hz}$ corner frequency (dashed curve); the eserine-slowed fluctuations are shown fit by the solid curve with corner frequencies of $4.2 \mathrm{~Hz}$ and $24 \mathrm{~Hz}$, and zero-frequency amplitudes of $2.8 \times 10^{-22}$ and $4.5 \times 10^{-24} \mathrm{~A}^{2}$ sec. Clamp potential $=-105 \mathrm{mV}$; average $\mathrm{ACh}$-induced currents were $35 \mathrm{nA}$ (Sea water) and $26 \mathrm{nA}$ (Eserine). Electrode noise contribution is seen above $100 \mathrm{~Hz}$. 
unaffected by eserine. We calculated $\gamma$ from the expression

$$
\gamma=\frac{S_{1}(0) 2 \pi f_{1}}{4 I\left(V_{m}-V_{\text {rev }}\right)}
$$

where $S_{1}(0)$ represents the zero-frequency intercept of the Lorentzian component with (lower) corner frequency $f_{1}, I$ is the mean amplitude of the ACh-induced current, and $\left(V_{m}-V_{\text {rev }}\right)$ is the electrochemical driving force on ion movement through the IPSC channel. In sea water, $\gamma=2.8 \pm 0.6 \mathrm{pS}(n=9)$; in eserine, $\gamma=3.0 \pm 1.3 \mathrm{pS}(n$ $=6$ ). Although these values agree with the $3.4 \pm 0.8 \mathrm{pS}$ at $20^{\circ} \mathrm{C}$ and $2.9 \pm 1.1 \mathrm{pS}$ at $17^{\circ} \mathrm{C}$ calculated from variance/mean ratios by Simmonneau et al. (1980) and Fossier et al. (1983a), three cautions are appropriate. First, determinations of $\gamma$ depend upon a knowledge of $V_{\mathrm{rev}}$, the reversal potential for ACh-induced current. Since $V_{\text {rev }}$ of this largely $\mathrm{Cl}^{-}$-dependent synapse can vary with the time during the course of an experiment, due to the $\mathrm{KCl}$ electrodes used, our determinations of $\left(V_{m}-V_{\text {rev }}\right)$ and therefore $\gamma$ may differ by 10 to $20 \%$ from actual values. Second, our calculations assume all of the mean current, $I$, is contributed by the slow process. Third, depending upon the interpretation of the process responsible for each of the two Lorentzian components, $\gamma$ may or may not be related to the mean single-channel conductance of the ACh-activated channel.

IPSCs and noise recorded in the same cells. In an attempt to compensate for cell-to-cell variation, we have recorded in the same cells both presynaptically evoked IPSCs and prolonged currents, for noise measurements, evoked by pressure ejection of $\mathrm{ACh}$ from micropipettes. In each of 10 cells, we recorded both IPSC and ACh noise in control sea water solutions. The average IPSC decay $\tau$ was $17.5 \pm 1.5$ msec. If the IPSC decay process is identified with the process producing the slow component of the Lorentzian curve, then the expression $f_{1}=$ $1 /\left(\begin{array}{lll}2 & \pi & \tau\end{array}\right)$ should hold (Anderson and Stevens, 1973; Colquhoun and Hawkes, 1977). The IPSC $\tau$ thus predicts an average $f_{1}=9.1 \mathrm{~Hz}$. However, in these same cells, the low corner frequency differs from the predicted value, with the best Lorentzian fits giving $f_{1}=6.3 \pm 0.4 \mathrm{~Hz}$ and $f_{2}=49 \pm 5 \mathrm{~Hz}$. For each of the 10 cells, the $f_{1}$ determined from noise spectra was compared to $1 /(2 \pi \tau)$ and was found to be $31 \pm 5 \%$ lower than would be predicted on the basis of a single channel-closing mechanism which also determined IPSC decay $\tau$. Possible sources for the discrepancy are considered under "Discussion."

In each of six neurons, we were able to sequentially record neurally evoked IPSCs and ACh noise in control sea water, then to treat the preparation with $1.5 \times 10^{-4}$ $M$ eserine and again record both IPSCs and noise (Fig. $3)$. In sea water, the IPSC $\tau=17 \pm 3 \mathrm{msec}$, similar to the $19 \mathrm{msec}$ found by Gardner and Stevens (1980), and corresponding to $f_{1}=9.4 \mathrm{~Hz}$. ACh spectra recorded in these six cells had $f_{1}=6.2 \pm 0.5 \mathrm{~Hz}$ and $f_{2}=52 \pm 7 \mathrm{~Hz}$. With eserine in the bath, IPSCs were prolonged, with $\tau$ increasing to $50 \pm 9 \mathrm{msec}$, a value corresponding to a Lorentzian curve with corner frequency $f_{1}=1 /(2 \pi \tau)=$ $3.2 \mathrm{~Hz}$. In these same cells, we recorded ACh spectra in the presence of eserine with $f_{1}=3.4 \pm 0.3 \mathrm{~Hz}$ and $f_{2}=$ $43 \pm 4 \mathrm{~Hz}$. In contrast, therefore, to the discrepancy between $f_{1}$ and $1 /(2 \pi \tau)$ seen in control sea water, the $f_{1}$ recorded in eserine agreed with the value predicted from the eserine-prolonged IPSC decay.

Effects of long-term treatment with eserine. When the preparation was perfused with sea water containing 1.5 $\times 10^{-4} \mathrm{M}$ eserine for periods greater than $30 \mathrm{~min}$, an additional decay step was superimposed on the eserineprolonged kinetic process in neurally evoked IPSCs. Figure 4 shows an example of this finding in a series of IPSCs recorded from the same neuron. IPSCs in control sea water are well fit by an exponential with $\tau=16 \mathrm{msec}$ (Fig. $4 A$ ). Ten minutes after eserine treatment (Fig. $4 B$ ) decay is still exponential, but prolonged, with $\tau=37$ msec. With longer exposure to eserine, we recorded the
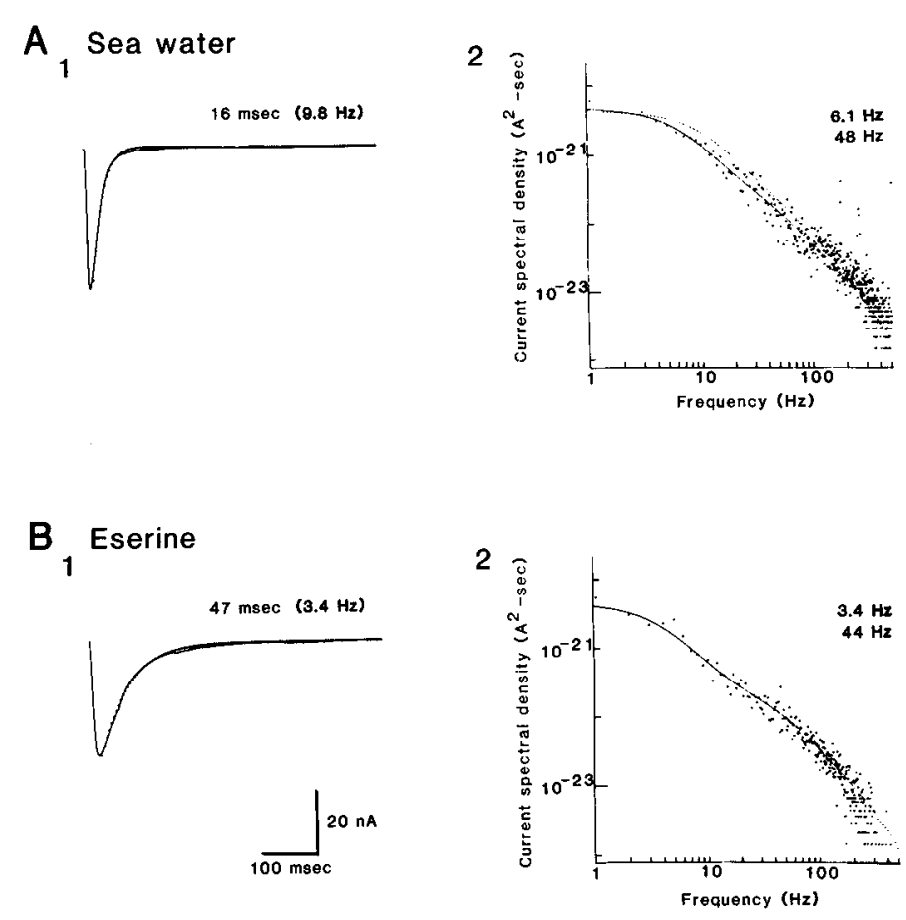

Figure 3. IPSC and ACh noise spectra recorded in the same cell are each prolonged by eserine. $A_{1}$, In control sea water, the decay phase of the IPSC (solid trace) is fit by a single exponential (dotted trace) with time constant $\tau=16 \mathrm{msec} . A_{2}$, The ACh noise spectrum recorded in the same cell is shown fit to each of two double Lorentzians. When the 16-msec $\tau$ of the IPSC was used to predict a lower corner frequency $f_{1}=1 /(2 \pi \tau)=$ $9.8 \mathrm{~Hz}$, and the upper corner frequency $f_{2}$ and amplitudes were adjusted for best fit, the inadequately fitting dashed curve was obtained. Acceptable fit to the spectrum was provided by a double Lorentzian with $f_{1}=6.1 \mathrm{~Hz}$ (different from that predicted by the IPSC $\tau$ ) and $f_{2}=48 \mathrm{~Hz}$, shown as a solid curve. Zero-frequency amplitudes were $4.7 \times 10^{-21}$ and $2.0 \times 10^{-22} \mathrm{~A}^{2}$ sec. $B$, Addition of $1.5 \times 10^{-4} \mathrm{M}$ eserine to the bath slows both IPSC decay $\left(B_{1}\right)$ and ACh fluctuations $\left(B_{2}\right)$. The IPSC in eserine decays with $\tau=47$ msec, equivalent to $f_{1}=3.4 \mathrm{~Hz}$, and the corresponding $\mathrm{ACh}$ noise spectrum is well fit by a double Lorentzian with $f_{1}=3.4 \mathrm{~Hz}, f_{2}=44 \mathrm{~Hz}$, and zero-frequency amplitudes of $4.1 \times 10^{-21}$ and $1.5 \times 10^{-22} \mathrm{~A}^{2}$-sec. IPSC decay $\tau$ and spectrum $f_{1}$ thus agree in eserine-treated preparations, but differ from one another in control sea water. $V_{m}=-120 \mathrm{mV}$; average ACh-induced current was $97 \mathrm{nA}$ (Sea water) and 36 nA (Eserine). Small spontaneous background events in the unaveraged IPSC records $A_{1}$ and $B_{1}$ appear as small deviations from exponential decay. 

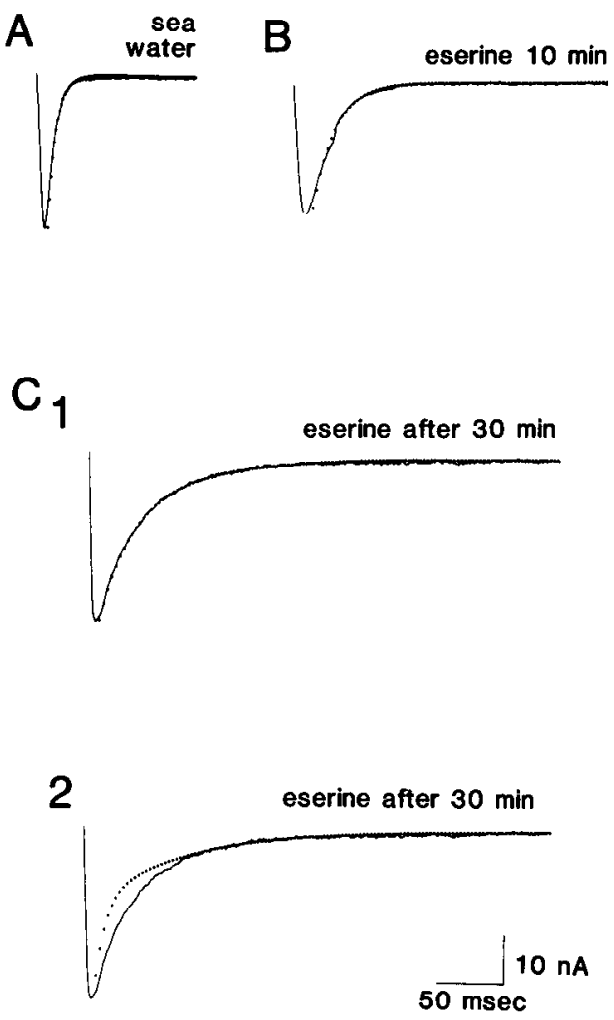

Figure 4. Eserine prolongs IPSCs by more than one mechanism. $A$, In control sea water, the decay tail of the IPSC (solid trace) has superimposed upon it a computer-generated exponential (dotted trace) with time constant $\tau=16$ msec. $B$, After $10 \mathrm{~min}$ in $1.5 \times 10^{-4} \mathrm{M}$ eserine, the IPSC again decays as a single exponential, now with $\tau=37 \mathrm{msec}$. $C$, After extended exposure to eserine, IPSC decay requires a double exponential for adequate fit. The additional decay process of $\tau=160 \mathrm{msec}$ fits the IPSC only when coupled to a $\tau=37$ msec decay component $\left(C_{1}\right)$; fit is inadequate when the $\tau=160 \mathrm{msec}$ process is coupled to a $\tau=16$ msec component $\left(C_{2}\right) . C_{1}$ and $C_{2}$ show the same current record. All three IPSCs recorded at a holding potential of $-139 \mathrm{mV} ; V_{\text {rev }}$ for this cell using $\mathrm{KCl}$ electrodes was $-42 \mathrm{mV}$.

IPSC shown as the middle and lower traces (Fig. 4C). This trace no longer decays as a single exponential: there is an additional decay process with $160 \mathrm{msec}$ time constant. The IPSC may be fitted by a double exponential, with a fast time constant of $39 \mathrm{msec}$, corresponding to the single-exponential decay seen after 10 min of eserine treatment. In contrast, we were unable to fit the same current when the fast time constant was set to $16 \mathrm{msec}$, the value of the decay seen in control sea water. In each of four cells, IPSCs seen after prolonged eserine treatment could be fitted by a double exponential. The fast $\tau$ was an average $2.7 \pm 0.3$ times the value of the IPSC $\tau$ seen in the same ccll before eserine treatment, and 0.87 \pm 0.08 times the value of the single eserine-prolonged decay $\tau$.

\section{Discussion}

\section{Eserine is more than an anticholinesterase}

We have suggested that eserine prolongs inhibitory postsynaptic currents by means of a direct effect on the receptor-channel complex, rather than via a block of $\mathrm{AChE}$ affecting transmitter removal. There is precedent for a mechanism of eserine action in molluscs distinct from AChE inhibition. Specific ACh responses in buccal ganglia of Navanax (Levitan and Tauc, 1972) and Aplysia (Ruff et al., 1981) are blocked by eserine via what is presumed to be a direct action on the receptor-channel complex. In support of this view, Carpenter et al. (1976) found that ACh receptors of Aplysia dactylomela have high affinity for eserine. The site for eserine action on the receptor was distinct from the $\mathrm{ACh}$-binding site, but close enough to the $\alpha$-bungarotoxin site to interfere with toxin binding. Affinity of this site for eserine was 50 times greater than for neostigmine.

Eserine prolongs channel kinetics. We have presented two sets of findings consistent with a direct effect of eserine prolonging the elementary event responsible for IPSC decay. The maintenance of single-exponential decay kinetics throughout the initial period of IPSC prolongation by eserine suggests that eserine modifies the process responsible for decay under control conditions, rather than substituting a new rate-limiting step. However, a mechanistic interpretation of this effect is difficult. We also find that eserine slows a process monitored by ACh fluctuation spectra. If the same process is responsible for IPSC decay, the slowing is evidence for a parallel direct effect of eserine on the IPSC and on a kinetic process underlying steady ACh-induced currents. Discrepancies between experimentally recorded ACh spectra and those predicted from IPSC decay are discussed in a separate section, below.

The slowing of ACh noise which we report is unlikely to be mediated via eserine's inhibition of AChE, as other anticholinesterases do not appear to affect elementary process kinetics. At Aplysia excitatory synapses, neostigmine did not affect spectra or voltage-jump relaxations (Ascher et al., 1978). In the same class of neurons we used in the present study, the organophosphorus anticholinesterase ecothiopate slows IPSC decay without effect on noise corner frequency (Fossier et al., 1983b). Similarly, neostigmine and phospholine have no effect on noise-revealed channel parameters (Fossier et al., 1983a).

Eserine is unlikely to act by delaying diffusion. Gardner and Stevens (1980) and Gardner (1980) argued that the single-exponential decay of IPSCs even after changes in temperature, $\mathrm{Ca}^{2+}$, and eserine suggested that the decay represented a single relaxation process, rather than a set of kinetically distinguishable processes whose combined kinetics appeared single exponential. They reasoned that if multiple processes contributed to decay, the above changes would be unlikely to alter several processes so as to consistently result in decay with single-exponential kinetics. We have thus applied an extension of this argument to the period of eserine wash-in. An additional point in favor of the hypothesis that decay in both the presence and absence of eserine is determined by the same mechanism is that the temperature sensitivity of IPSC decay $\tau$ appears unchanged by eserine treatment (Gardner and Stevens, 1980).

We argue against the hypothesis that eserine treatment results in a new rate-limiting step, such as delayed 
diffusion (Katz and Miledi, 1973), on the grounds that, during wash-in, the convolution of, say, a lengthening transmitter concentration driving function and an exponential channel-related decay process would be likely to produce multi-component decay. However, in a model system in which both a voltage-dependent channel-closing step and slow removal of transmitter by diffusion and hydrolysis were assumed, computed prolonged endplate currents (EPCs) were found to decay exponentially after $90 \%$ block of AChE (Kordas, 1977). Similarly, Magleby and Terrar (1975) postulated a new rate-limiting step determining EPC decay after edrophonium treatment, but they recorded single-exponential decay kinetics during wash-in. Although their semilogarithmic plots show decay only to $22 \%$ of peak (about $1 \frac{1}{2} 2$ time constants), and so might miss an additional small decay component, their data suggest that either: (1) they were incorrect in their suggestion that a new process contributes to decay, or else (2) our assumption that such a substitution of decay processes must produce multi-component decay is incorrect.

Two further points are inconsistent with delayed diffusion as determinant of IPSC decay at these Aplysia synapses. There is no evidence for a narrow subsynaptic cleft in Aplysia similar to the one found at the frog endplate. Moreover, the AChE inhibitor ecothiopate prolongs carbachol responses in buccal ganglia neurons, leading Fossier et al. (1983b) to conclude that invoking delayed diffusion in this preparation would require $\mathrm{AChE}$ inhibition itself to directly alter the number of available ACh receptors.

\section{Interpretation of ACh noise spectra}

Gardner and Stevens (1980) found in these cells an average IPSC decay $\tau$ of $19 \mathrm{msec}$, and suggested that this decay reflected the lifetime of an elementary postsynaptic event. Such a process would be consistent with a Lorentzian spectrum with corner frequency of $8.5 \mathrm{~Hz}$. When ACh noise was recorded, in separate experiments on the same population of neurons, and fitted by double Lorentzians with $f_{1}=7.8 \mathrm{~Hz}$, Gardner and Stevens (1980) used this approximate correspondence to argue that the $f_{1}$ process underlay IPSC decay. In this study, however, we have recorded IPSCs and ACh noise from the same cell in the same experiment and have found $f_{1}$ to be $31 \%$ lower than the value predicted by $\tau$. This discrepancy is seen only before eserine treatment; after slowing by eserine, $f_{1}=1 /(2 \pi \tau)$. A possible interpretation of these data is that the parallel slowing of $\tau$ and $f_{1}$ is coincidental and that IPSC decay reflects transmitter removal; we find this hypothesis unattractive.

In these neurons, Fossier et al. $(1983 \mathrm{a}, \mathrm{b})$ report noise spectra with $f_{1}$ of $7.6 \mathrm{~Hz}$ at $20^{\circ} \mathrm{C}$, midway between the $6.3 \mathrm{~Hz}$ we measured from noise and the $9.1 \mathrm{~Hz}$ predicted by our values for IPSC decay. Their spectra, like ours, show somewhat larger scatter from the best Lorentzian fit than do those recorded in other preparations. However, their results, although providing independent support for the shape of our spectra, and for approximate values of $f_{1}$ and $\tau$, neither confirm, contradict, nor explain our finding of a $\tau-f_{1}$ discrepancy.

Assuming that standard kinetic models (Colquhoun and Hawkes, 1977; Dionne, 1981) account for the postsynaptic events we have measured, one of three mechanisms is necessary to account for the discrepancy between $\tau$ and $f_{1}$ in the absence of eserine. They are: an additional noise source, synaptic or nonsynaptic; processes altering the elementary event lifetime in one case or the other; or violation of the assumption of low agonist concentration underlying the relation $f_{1}=1 /(2 \pi \tau)$. Each of these is considered below.

Additional spectral components. A discrepancy between $\tau$ and corner frequency was also found by Colquhoun et al. (1977) at the neuromuscular junction. In their case, the noise corner frequency was $26 \%$ faster than would be predicted by miniature EPC decay. They offered as a possible explanation the presence of contamination by an additional noise source, whose effect is to shift the apparent corner frequency. A similar invocation of either excess $1 / f$ noise or else an additional Lorentzian component could explain our spectra. The additional Lorentzian component might reflect noise contributions from a population of extrasynaptic $\mathrm{ACh}$-activated channels not accessible to nerve release transmitter, but activated by pipette-delivered agonist (Dreyer et al., 1976; Neher and Sakmann, 1976; Dionne, 1981).

However, a more intriguing candidate for additional noise source is available, based upon the common finding that elementary event kinetics are agonist dependent. Partial contamination by a different cholinergic agonist, producing longer channel lifetime, might give an additional component. On these neurons, choline itself is an effective agonist (Ruff et al., 1981), likely to be present during pressure ejection of $\mathrm{ACh}$, both via $\mathrm{AChE}-\mathrm{me}$ diated hydrolysis of released $\mathrm{ACh}$ and as a contaminant of the ACh solution in the pipette. If the amplitude of the response to choline were small, or the corner frequency near $f_{1}$ or $f_{2}$, the apparent $f_{1}$ or $f_{2}$ might appear shifted instead of being itself resolved as a separate component. The difficulty of fitting spectra to multiple Lorentzian plots produced by processes with similar kinetics has been pointed out by Neher and Stevens (1977). To lower the apparent $f_{1}$ in control sea water, this process would have to have a corner frequency slower than $6 \mathrm{~Hz}$. After treatment with eserine, block of AChE would reduce choline production, thus lowering the amplitude of the contaminating component and removing the $\tau-f_{1}$ discrepancy. This hypothesis is, of course, testable: it predicts both that pipette-delivered choline should produce a spectrum with $f_{1}<6.3 \mathrm{~Hz}$ and that AChE inhibitors other than eserine, without direct effect on elementary process lifetime, should increase the apparent $f_{1}$ of spectra in which choline contamination is suspected.

Elementary event kinetics produced subsynaptically, and via agonist ejection, are unlikely to differ. We have attempted to eliminate factors which might alter the elementary event lifetime recorded by one method but not the other. Rate constants in several synaptic systems depend on $V_{m}$, although these Aplysia synapses seem to be voltage independent (Gardner, 1980; Gardner and Stevens, 1980). However, both IPSCs and noise were recorded at the same values of $V_{m}$, in a system in which the synapses are electrically close to the cell body. We have also considered the possibility that prolonged ionic 
current evoked by pressure-ejected $\mathrm{ACh}$, or a consequent alteration in ionic concentration, might affect lifetime. Loss of $\mathrm{Cl}^{-}$at the values of $V_{m}$ we used seems an unlikely mechanism for prolongation, as maintained recording with $\mathrm{KCl}$ electrodes and consequent gain of $\mathrm{Cl}^{-}$did not shorten IPSCs. Large $\mathrm{Cl}^{-}$currents might themselves alter lifetime, but we cannot then explain the lack of a similar effect with eserine.

Violations of the low concentration limit are unlikely. Finally, standard models specify $f_{1}=1 /(2 \pi \tau)$ only for low agonist concentrations. As this low concentration limit is violated, decay is speeded up (Neher and Sakmann, 1976; Colquhoun and Hawkes, 1977; Dionne, 1981). If the low concentration limit were violated during pressure ejection or iontophoresis of agonist, the corner frequency would be expected to increase: $f_{1}>1 /(2 \pi \tau)$. However, we observed corner frequencies slower than predicted: $f_{1}<1 /(2 \pi \tau)$. Since the IPSC is thus apparently faster than the equivalent noise process, is it possible that the low concentration limit is violated during the IPSC? If the violation were for only a short time at or near the peak of the IPSC, decay would be initially fast, then would slow to $\tau=1 /\left(2 \pi f_{1}\right)$ for the remainder of the tail. However, we observed for the entire IPSC a uniform decay $\tau=1 /\left(2 \pi f_{1}\right)$, requiring the absurd postulate that the low concentration limit is violated during the entire duration of the IPSC, including the tail.

Of the three sets of explanations advanced to explain the $\tau-f_{1}$ discrepancy, we find the possibility of contamination by an additional noise source, perhaps due to agonist activity of choline, the most attractive.

\section{References}

Anderson, C. R., and C. F. Stevens (1973) Voltage clamp analysis of acetylcholine produced end-plate current fluctuations at frog neuromuscular junction. J. Physiol. (Lond.) 235: 655-691.

Ascher, P., A. Marty, and T. O. Neild (1978) Life time and elementary conductance of the channels mediating the excitatory effects of acetylcholine in Aplysia neurones. J. Physiol. (Lond.) 278: 177-206.

Carpenter, D. O., L. A. Greene, W. Shain, and Z. Vogel (1976) Effects of eserine and neostigmine on the interaction of $\alpha$ bungarotoxin with Aplysia acetylcholine receptors. Mol. Pharmacol. 12: 999-1006.

Colquhoun, D., and A. G. Hawkes (1977) Relaxation and fluctuations of membrane currents that flow through drug-operated channels. Proc. R. Soc. Lond. Biol. 199: 231-262.

Colquhoun, D., W. A. Large, and H. P. Rang (1977) An analysis of the action of a false transmitter at the neuromuscular junction. J. Physiol. (Lond.) 266: 361-395.

Dionne, V. E. (1981) The kinetics of slow muscle acetylcholineoperated channels in the garter snake. J. Physiol. (Lond.) 310: 159-190.

Dionne, V. E., and R. L. Parsons (1981) Characteristics of the acetylcholine-operated channel at twitch and slow fibre neuromuscular junctions of the garter snake. J. Physiol. (Lond.) 310: 145-158.

Dreyer, F., C. Walther, and K. Peper (1976) Junctional and extrajunctional acetylcholine receptors in normal and denervated frog muscle fibres. Pflugers Arch. 366: 1-9.
Fossier, P., G. Baux, and L. Tauc (1983a) Possible role of acetylcholinesterase in regulation of postsynaptic receptor efficacy at a central inhibitory synapse of Aplysia. Nature 301: 170-172.

Fossier, P., G. Baux, and L. Tauc (1983b) Direct and indirect effects of an organophosphorus acctylcholinesterase inhibitor and of an oxime on a neuro-neuronal synapse. Pflugers Arch. 396: 15-22.

Gage, P. W., and R. N. McBurney (1975) Effects of membrane potential, temperature and neostigmine on the conductance change caused by a quantum of acetylcholine at the toad neuromuscular junction. J. Physiol. (Lond.) 244: 385-407.

Gardner, D. (1977) Voltage-clamp analysis of a self-inhibitory synaptic potential in the buccal ganglia of Aplysia. J. Physiol. (Lond.) 264: 893-920.

Gardner, D. (1980) Membrane-potential effects on an inhibi tory post-synaptic conductance in Aplysia buccal ganglia. J. Physiol. (Lond.) 304: 165-180.

Gardner, D., and E. R. Kandel (1977) Interconnections of identified multiaction interneurons in buccal ganglia of $A p l y$ sia. J. Neurophysiol. 40: 349-361.

Gardner, D., and C. F. Stevens (1980) Rate-limiting step of inhibitory post-synaptic current decay in Aplysia buccal ganglia. J. Physiol. (Lond.) 304: 145-164.

Hartzell, H. C., S. W. Kuffler, and D. Yoshikami (1975) Postsynaptic potentiation: Interaction between quanta of acetylcholine at the skeletal neuromuscular synapse. J. Physiol. (Lond.) 251: 427-463.

Katz, B., and R. Miledi (1973) The binding of acetylcholine to receptors and its removal from the synaptic cleft. J. Physiol. (Lond.) 231: 549-574.

Kordas, M. (1972) An attempt at an analysis of the factors determining the time course of the end-plate current. I. The effects of prostigmine and of the ratio of $\mathrm{Mg}^{2+}$ to $\mathrm{Ca}^{2+}$. J. Physiol. (Lond.) 224: 317-332.

Kordas, M. (1977) On the role of junctional cholinesterase in determining the time course of the end-plate current. J. Physiol. (Lond.) 270: 133-150.

Levitan, II., and L. Tauc (1972) Acetylcholine receptors: Topographic distribution and pharmacological properties of two receptor types on a single molluscan neurone. J. Physiol. (Lond.) 222: 537-558.

Magleby, K. L., and C. F. Stevens (1972) The effect of voltage on the time course of end-plate currents. J. Physiol. (Lond.) 223: 151-171.

Magleby, K. L., and D. A. Terrar (1975) Factors affecting the time course of decay of end-plate currents: A possible cooperative action of acetylcholine on receptors at the frog neuromuscular junction. J. Physiol. (Lond.) 244: 467-495.

Neher, E., and B. Sakmann (1976) Noise analysis of drug induced voltage clamp currents in denervated frog muscle fibres. J. Physiol. (Lond.) 258: 705-729.

Neher, E., and C. F. Stevens (1977) Conductance fluctuations and ionic pores in membranes. Annu. Rev. Biophys. Bioeng. 6: $345-381$.

Ruff, R. L., R. L. White, and D. Gardner (1981) Choline sensitivity of postsynaptic receptors in Aplysia buccal ganglia. Soc. Neurosci. Abstr. 7: 838.

Simonneau, M., L. Tauc, and G. Baux (1980) Quantal release of acetylcholine examined by current fluctuation analysis at an identified neuro-neuronal synapse of Aplysia. Proc. Natl. Acad. Sci. U. S. A. 77: 1661-1665.

White, R. L., and D. Gardner (1980) Channel lifetime at inhibitory cholinergic synapses is prolonged by eserine. Soc. Neurosci. Abstr. 6: 778 . 